\title{
Rehearsal for Assessment of atmospheric optical Properties during biomass burning Events and Long-range transportation episodes at Metropolitan Area of São Paulo-Brazil (RAPEL)
}

Fábio J. S. Lopes ${ }^{1, *}$, Juan Luis Guerrero-Rascado ${ }^{2,3}$, Jose A. Benavent-Oltra ${ }^{2,3}$, Roberto Román $^{2,3}$, Gregori A. Moreira ${ }^{1,2,3}$, Marcia. T. A. Marques ${ }^{1}$, Jonatan J. da Silva ${ }^{1}$, Lucas Alados-Arboledas ${ }^{2,3}$, Paulo Artaxo ${ }^{4}$ and Eduardo Landulfo ${ }^{1}$

${ }^{1}$ Center for Lasers and Applications (CLA), Nuclear and Energy Research Institute (IPEN), Brazil, *fabiolopes@usp.br

${ }^{2}$ Institute for Earth System Research (IISTA-CEAMA), Spain

${ }^{3}$ Dpt. Applied Physics, Faculty of Sciences, University of Granada, Spain

${ }^{4}$ Institute of Physics, University of São Paulo, Brazil

\begin{abstract}
During the period of August-September 2016 an intensive campaign was carried out to assess aerosol properties in São Paulo-Brazil aiming to detect long-range aerosol transport events and to characterize the instrument regarding data quality. Aerosol optical properties retrieved by the GALION - LALINET SPU lidar station and collocated AERONET sunphotometer system are presented as extinction/backscatter vertical profiles with microphysical products retrieved with GRASP inversion algorithm.
\end{abstract}

\section{INTRODUCTION}

According to the Intergovernmental Panel on Climate Change (IPCC) [1], anthropogenic aerosols are responsible for a negative radiative forcing for climate, widely contributing to cooling or warming the atmosphere through different processes such as aerosol-radiation and aerosol-cloud interactions. However, due to lack of observations and the difficult in measurements of important aerosol parameters, considerable uncertainties remain in assessments of long-term trends of global properties of aerosols. At this point, an important issue must be addressed: it is necessary to increase the number of observational stations and the experimental field campaigns to increase the global observation of aerosol optical and phys- ical properties, and consequently, improve the climate numeric model validation. The development of aerosol measurement networks, with rigorous and systematic protocols of measurements is an important step to increase the reliability of aerosol measurements. In this context, the Latin America Lidar network (LALINET) [2], has been monitoring the vertical distribution of particle optical properties since 2001, and started to be operative with systematic measurements since 2013. LALINET has the purpose of developing an accurate database of vertical distribution of aerosol over South America providing data for air quality, information of aerosol microphysical properties and other atmospheric components such as water vapour and clouds, also, to provide quality assurance data for atmospheric satellite missions such as CALIPSO [4], and the future ESA's mission ADM-Aeolus and EarthCARE [3]. Focusing on the validation processes of ESA's mission, LALINET is working to implement quality assurance standards based on EARLINET procedures to increase the capability to provide a reliable dataset. During August and September of 2016 the LALINET São Paulo station (SPU) started a rehearsal performing a preproject field experiment to gather a high quality dataset to assess the atmospheric optical properties during biomass burning events and longrange transportation episodes at Metropolitan Area of São Paulo (MASP)-Brazil (RAPEL campaign). During RAPEL were detected at 
least 5 episodes of biomass burning (BB) transportation. In this work the aerosol properties and microphysical properties using the GRASP (Generalized Retrieval of Atmosphere and Surface Properties) inversion algorithm [5] were retrieved.

\section{INSTRUMENTATION AND METHOD- OLOGY}

An elastic and Raman lidar system (MSP-Lidar I) installed at the Nuclear and Energy Research Institute (IPEN) was employed to measure the particle extinction and backscatter coefficients and, thus, the respective particle (extinction-tobackscatter) lidar ratio at 532 and $355 \mathrm{~nm}$. The configuration of SPU lidar station for RAPEL campaign were composed by four detection channels, 355, 387, 532 and $607 \mathrm{~nm}$, all in both AN and PC detection modes. The scheduled measurements in this particular campaign covered the period from $11^{\text {th }}$ August to $30^{\text {th }}$ September. Measurements were performed from Monday to Friday during daytime, and Monday and Thursday at nighttime. In total, the number of scheduled days was 37 , split into 32 days with performed measurements $(86.5 \%)$. The RAPEL campaign was coordinated during the Southern hemisphere winter season, considered the dry season at the Southeastern part of Brazil, where SPU lidar station is located. During the winter/dry season São Paulo city can experience high pollution episodes due poor dispersion conditions and aerosol biomass burning transportation from different parts of Brazil and South America continent. During the campaign there were at least 5 possible days with biomass burning transportation occurrence. The selected days with lidar measurements to be studied were analyzed to derive optical properties at the available wavelengths and particle backscatter coefficient profiles. In addition, ancillary information was used: optical and microphysical column integrated aerosol proper- ties derived from a co-located AERONET sunphotometer, radiosoundings launched at Campo de Marte station, backtrajectories at 6 different heights to investigate the air masses origin from HYSPLIT model.

\section{RESULTS}

As a first step, AERONET aerosol optical depth (AOD) retrievals for cloud-free days during the campaign period are derived. The mean values and the standard deviation of AOD at $532 \mathrm{~nm}$ retrieved from AERONET were 0.22 \pm 0.15 during August to September of 2016. For the RAPEL period, the number of focus fires in the brazillian territory increased around $65 \%$ compared to the wet season, according to brazillian National Institute For Space Research INPE (http://www.inpe.br/queimadas/). Figure 1 shows the range corrected signal (RCS) at $532 \mathrm{~nm}$ measured by SPU station during a BB case on August $16^{\text {th }} 2016$. It can be seen that most part of aerosol are confined into the atmospheric boundary layer (ABL) region, which should be from local sources. However, there were some decoupled aerosol plumes above the PBL, between the altitude of 2 to $3.5 \mathrm{~km}$ (a.g.l). Applying the Klett-Fernald-Sasano inversion method by tuning the initial lidar ratio assumption with the AOD values retrieved from AERONET, particle backscatter profiles at 532 $\mathrm{nm}$ were retrieved, as can be seen in figure 1 (in red). For the mean profiles between 19:00 to 19:30 UTC and 19:30 to 20:00 UTC, a lidar ratio of $70 \pm 14 \mathrm{sr}$ was obtained for both profiles. In order to investigate the aerosol plumes between 2 to $3.5 \mathrm{~km}$ detected by the SPU station, HYSPLIT trajectory model was used to calculate backward trajectories and derive information about from where, when and which altitude aerosols layers were transported to São Paulo. Five-day back-trajectories of air-masses starting at the SPU station were calculated using the GDAS database from Global Data Assimilation 
System, for six different altitudes ranging from 1000 to $3800 \mathrm{~m}$ above ground level (a.g.l.). The back-trajectories starting at 19 UTC and with altitude level from 2000 to $2500 \mathrm{~m}$ a.g.l. came originally from North-Western region of Brazil, and the back-trajectories with altitude between 3000 to $3500 \mathrm{~m}$ a.g.l. came from Bolivia region. Both locations have intense burning events during this period of the year, thus it can be expected that BB aerosols were advected from this source region to São Paulo, as depicted in figure 2.

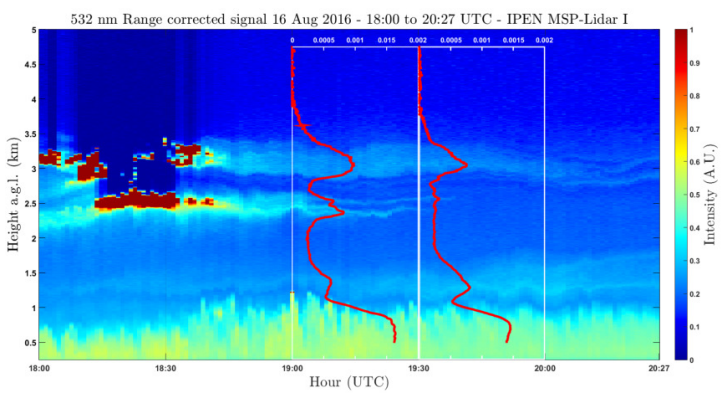

Figure 1: $532 \mathrm{~nm}$ range corrected signal on August $16^{\text {th }} 2016$ measured by SPU Station and the particulate backscatter profiles (red) retrieved during RAPEL.

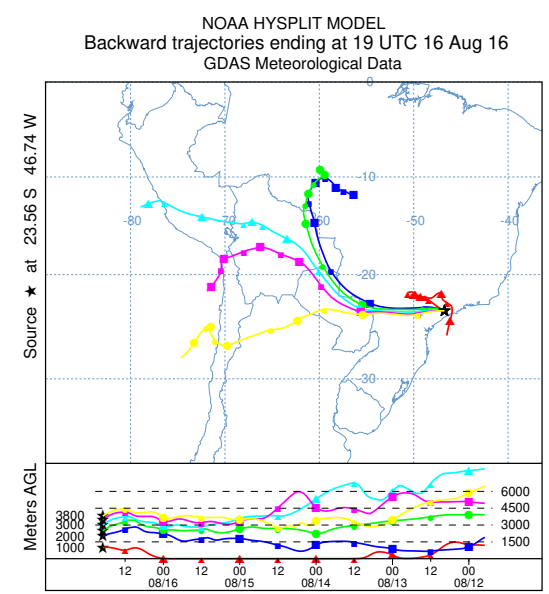

Figure 2: Five-day backward trajectories ending at SPU station at 19 UTC, at different levels 1000, 2000, 2500, 3000, 3500 and $3800 \mathrm{~m}$ a.g.l.) on August $16^{\text {th }} 2016$.
In order to derive complementary information of the aerosol load at São Paulo atmosphere combining the SPU lidar and AERONET retrieved data, GRASP inversion algorithm were used to retrieve optical and microphysical parameters on the vertical distribution and compared with lidar measurements, using as input the AOD and sky radiances at $440,675,870$ an $1020 \mathrm{~nm}$, and also the RCS at 355 and $532 \mathrm{~nm}$. Figure 3 shows that the aerosol size distribution values obtained from GRASP and AERONET are in good agreement. It also shows that the size of the most part of aerosol presented in the atmosphere for this measurement days was fine mode aerosol, which is a characteristic of $\mathrm{BB}$ aerosol type.

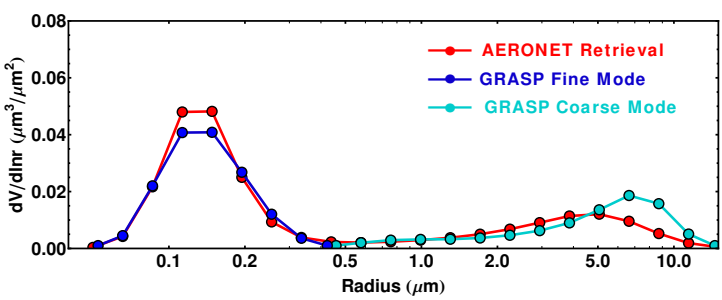

Figure 3: GRASP (blue and cyan) and AERONET (red) size distribution for August 16 ${ }^{\text {th }} 2016$ (19:15 UTC) over SPU station.

Particle backscatter coefficient at $532 \mathrm{~nm}$ derived from GRASP shows that aerosol fine mode is predominant in the profile for this measurements, as can be seen in figure 4 (left panel). It also can be seen a good agreement between $532 \mathrm{~nm}$ total backscatter coefficient derived from GRASP and that on retrieved by the SPU station using the KlettFernald method. The $532 \mathrm{~nm}$ lidar ratio profile retrieved by GRASP inversion, right panel of figure 4 , shows a mean lidar ratio of $75 \mathrm{sr}$ for the aerosol plumes between 2 to $3.5 \mathrm{~km}$ of altitude, which is the typical value for aerosol from BB type. The vertical distribution of single scattering albedo shows values between 0.70 and 0.85 , which can be considered low values for Brazilian BB aerosol type. However, consid- 
ering that the aerosol plume were transported from the North-Western region of Brazil to São Paulo, their properties may have been modified due the increase of humidity at the São Paulo atmosphere and this hypothesis will be investigated.

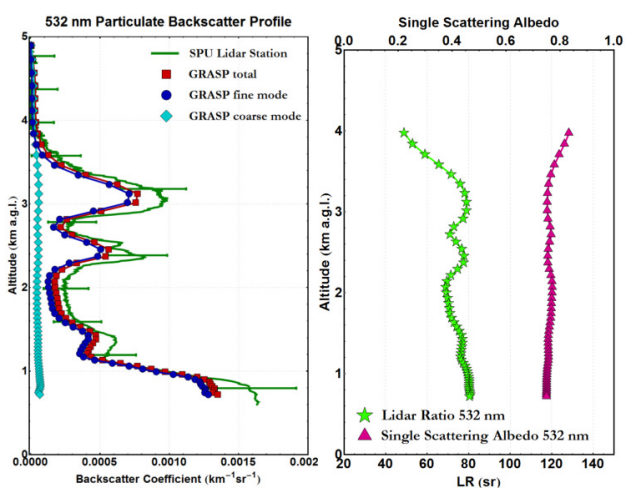

Figure 4: $532 \mathrm{~nm}$ particle backscatter profile and retrieved from GRASP (left panel) and $532 \mathrm{~nm}$ lidar ration and single scattering albedo profiles for August $16^{\text {th }} 2016$ (19:30 UTC) over SPU station.

\section{CONCLUSIONS}

The work presented a case study of of biomass burning transportation detected during the RAPEL campaign in the framework of a preproject field experiment in order to obtain a high quality data set to assessment of particle properties. Particle backscatter coefficient at $532 \mathrm{~nm}$ and HYSPLIT back-trajectories indicated the presence of aerosol plumes transported from Central-Western region of Brazil to São Paulo. Combination of sun/sky photometer and lidar measurements applied to GRASP algorithm show to be a power tool to derive microphysical parameters of aerosol on vertical scale. Also, GRASP results were in agreement with AERONET and lidar retrievals. GRASP $532 \mathrm{~nm}$ particle backscatter profile shows the predominance of fine mode aerosol type, and the lidar ratio profile retrieved from GRASP confirmed the presence of $\mathrm{BB}$ aerosol type.

\section{ACKNOWLEDGEMENTS}

The authors would like to thank for the support given by the following funding agencies: FAPESP (Projects 2015/12793-0 and 2016/09151-0), CNPq (Universal project 471798/2013-4). This work was supported by the University of Granada through "Plan Propio. Programa 9 Convocatoria 2013, by the Andalusia Regional Government through project P12-RNM-2409, by the Spanish Ministry of Economy and Competitiveness through projects CGL2013-45410-R and CGL2016-81092-R and by the European Union's Horizon 2020 research and innovation programme through project ACTRIS-2 (grant agreement No 654109).

\section{References}

[1] T. F. Stocker et al., 2013: Climate Change 2013: The Physical Science Basis. Contribution of Working Group I to the Fifth Assessment Report of the Intergovernmental Panel on Climate Change, Cambridge University Press, Cambridge, United Kingdom and New York, NY, USA, 1535 pp. doi:10.1017/CBO9781107415324.

[2] J. L. Guerrero-Rascado et al., 2016: Latin American Lidar Network (LALINET) for aerosol research: Diagnosis on network instrumentation, J Atmos Sol-Terr Phy, 138-139, 112-120. Doi:10.1016/j.jastp.2016.01.001.

[3] A. Hélière et al., 2016: Development status of the EarthCARE Mission and its atmospheric Lidar, Proc. SPIE, Earth Observing Systems XXI, 9972, 997215. Doi:10.1117/12.2235412.

[4] F. J. S. Lopes et al., 2013: Evaluating CALIPSO's $532 \mathrm{~nm}$ lidar ratio selection algorithm using AERONET sun photometers in Brazil, Atmos. Meas. Tech., 6, 3281-3299. Doi:10.5194/amt-6-3281-2013.

[5] O. Dubovik et al., 2011: Statistically optimized inversion algorithm for enhanced retrieval of aerosol properties from spectral multi-angle polarimetric satellite observations, Atmos. Meas. Tech., 4, 975-1018. Doi:10.5194/amt-4-975-2011. 